\title{
Saúde da criança: produção do sujeito cidadão
}

\section{Child Health: production of a citizen-subject}

\section{Lutiane de Lara*}

Universidade Federal do Rio Grande do Sul - UFRGS, Porto Alegre, Rio Grande do Sul, Brasil

\author{
Neuza Maria de Fátima Guareschi** \\ Universidade Federal do Rio Grande do Sul - UFRGS, Porto Alegre, Rio Grande do \\ Sul, Brasil
}

\author{
Simone Maria Hüning*** \\ Universidade Federal de Alagoas - UFAL, Maceió, Alagoas, Brasil
}

\begin{abstract}
RESUMO
Este artigo tem como objetivo discutir as práticas que envolvem a saúde da criança no Sistema Único de Saúde (SUS), a partir do documento "Caderneta de Saúde da Criança: passaporte da cidadania", que propõe atenção integral à saúde dessa população. Compreendendo a saúde como uma estratégia biopolítica, vamos investigar esta proposta como um investimento para a vida do sujeito cidadão, adotando para tal uma perspectiva teórica foucaultiana. Assim sendo, ressaltamos que os cuidados com a saúde da criança não estão apenas voltados para a promoção de uma política pública, mas, sobretudo, aponta para uma estratégia mais abrangente no que se refere à produção do sujeito cidadão, enquanto sujeito de direitos.
\end{abstract}

Palavras-chave: Saúde da Criança, SUS; biopolítica; sujeito de direitos.

\begin{abstract}
This paper aims to discuss the practices on child health in Brazilian National Health System (SUS) considering the document entitled "Child Health Card: a passport to citizenship", which proposes integral attention to the health of that population. Understanding health as a bio-political strategy, from a Foucauldian theoretical perspective, we intend to think about this proposal of health care as something that aims at investing in life for the production of a citizen-subject. We attempt to show that health care goes beyond health promotion, pointing towards a strategy of production of a citizen-subject as a subject of rights.
\end{abstract}

Keywords: child health; SUS; bio-politics; subject of rights. 


\section{I ntrodução}

Este artigo realiza um exercício de problematização das práticas de saúde em torno da criança, previstas pelo Sistema Único de Saúde (SUS), a partir do documento Caderneta de Saúde da Criança: passaporte da cidadania (BRASIL, 2007). Este documento foi produzido pelo Ministério da Saúde, através do SUS. É utilizado como manual de orientação dos cuidados que devem ser dirigidos às crianças de zero a dez anos pelos profissionais de saúde e, principalmente, pelos pais e/ou cuidadores. Muitos dos discursos produzidos pela Caderneta são incorporados não só pelos pais, cuidadores e profissionais, como também por pessoas que não estão diretamente envolvidas com o cuidado de crianças, mas que os tomam como referências do que seja uma atenção adequada para elas. A Caderneta está disponível no portal do Ministério da Saúde como um documento inserido nas práticas de saúde direcionadas à criança, mais especificamente na Atenção à Saúde, como uma ação programática estratégica - Saúde da Criança.

Esta problematização parte da perspectiva de que o saber está sempre atrelado ao exercício de poder e de que as verdades produzidas pelos conhecimentos se manifestam na produção de modos de ser sujeito. Portanto, a produção de saberes sobre a saúde não deve ser entendida como evolução e progresso das ciências, mas a partir do entendimento de que saberes nunca são neutros e sempre são políticos. Os saberes estão amarrados em relações de poder implicadas em diferentes práticas sociais e se fundam de acordo com as verdades que procuram legitimar. Saber e poder constituem-se mutuamente, e

não há relação de poder sem a constituição de um campo de saber, como também, reciprocamente, todo saber constitui novas relações de poder. Todo ponto de exercício do poder é, ao mesmo tempo, um lugar de formação de saber (MACHADO, 2004, p. XXI).

Assim sendo, os saberes sobre a saúde da criança, na medida em que afirmam verdades sobre ela, classificam-na e delimitam-na segundo determinados modelos de ser e viver a saúde das crianças.

Os domínios de saber/poder, a partir do século XIX, têm produzido a criança e as pessoas em geral através de mecanismos de governo biopolíticos. A biopolítica é uma estratégia de governo das populações e dos indivíduos. Trata-se de uma tomada do poder sobre a vida das pessoas como uma estatização do biológico. Neste artigo, essa noção é importante porque aponta como a vida, a saúde e os modos de viver foram colocados como uma preocupação e alvo de investimento das práticas do Estado. A biopolítica abarca as técnicas de poder 
centradas no corpo do indivíduo como características de uma anátomo-política, que se ocupa do disciplinamento dos corpos. Este disciplinamento consiste em procedimentos de poder que asseguram a distribuição espacial dos corpos individuais e a organização de um espaço de visibilidade desses corpos (como numa sala de aula, por exemplo). É uma técnica que procura vigiar, adestrar e, eventualmente, castigar os indivíduos (FOUCAULT, 2005). Trata-se de uma técnica de poder que se aplica à vida das pessoas como massa global, uma biopolítica. Diz respeito aos processos de conjunto específicos da vida - como o nascimento, a morte, a enfermidade como fenômenos gerais relativos à vida que passarão a ser alvo de conhecimento e investimento do Estado para que se maximizem as forças da população. A biopolítica faz a gestão da vida e assegura não tanto a disciplina dos corpos, mas a regulação da vida. A biopolítica dá visibilidade aos processos que vinculam práticas de saúde e governo na produção dos sujeitos criança. Tomamos as intervenções sobre a saúde das crianças como um conjunto de práticas que instituíram e instituem modos de ser sujeito, ou seja, os modos pelos quais os seres humanos se tornam sujeitos (FOUCAULT, 2005).

\section{O SUS e a Saúde da Criança}

Para situar a Caderneta de Saúde da Criança: passaporte da cidadania - é preciso contextualizar os movimentos que aconteceram a partir do final da década de 1970. Este período foi importante para a produção de outros modelos de atenção à saúde da população. Um processo que esteve diretamente envolvido com os questionamentos das bases teóricas, políticas e econômicas do fazer saúde no Brasil. 0 Brasil vivia os últimos anos da Ditadura Militar, e era influenciado pelos movimentos internacionais, os quais apontavam para outros modos de fazer saúde. Entre esses movimentos, destaca-se a Declaração de Alma-Ata, Conferência Internacional sobre cuidados primários de saúde (ALMA-ATA, 1978), estabelecendo como prioridade a proposta de atenção básica como uma crítica às intervenções em saúde, especialmente àquelas que investem apenas na recuperação da saúde e na prevenção da doença. A saúde foi definida como completo bem-estar físico, mental e social e não apenas como ausência de doença ou enfermidade. A saúde foi assumida como um direito humano fundamental, e oferecer os melhores níveis de saúde passou a ser a mais importante meta social mundial. Assumiu-se que a promoção e proteção da saúde dos povos são essenciais para o contínuo desenvolvimento econômico e social e contribui para a melhor qualidade de vida e para a paz mundial. As ações de saúde da criança, assim como as demais ações de saúde, passariam a ser consideradas em seu âmbito de cuidados primários 
de saúde. A saúde da criança passaria a abarcar a infância em seu cotidiano - a infância nos seus processos de vida. Considerava-se cuidados primários de saúde:

\begin{abstract}
educação, no tocante a problemas prevalecentes de saúde e aos métodos para sua prevenção e controle, promoção da distribuição de alimentos e da nutrição apropriada, previsão adequada de água de boa qualidade e saneamento básico, cuidados de saúde materno-infantil, inclusive planejamento familiar, imunização contra as doenças infecciosas, prevenção e controle de doenças localmente endêmicas, tratamento apropriado de doenças e lesões comuns e fornecimento de medicamentos essenciais (ALMA-ATA, 1978, p. 2).
\end{abstract}

Nos anos de 1970, o movimento de Saúde Coletiva no Brasil estendeu o movimento de crítica da medicina social às demais profissões da área da saúde (MATTOS, 2001). Já na década de 1970, cria-se a Associação Brasileira de Pós-Graduação em Saúde Coletiva - ABRASCO - e do Centro Brasileiro de Estudos da Saúde - CEBES. Movimentos estes que deram subsídio para o desenvolvimento da reforma sanitária, que formulou críticas à medicalização da sociedade e ao saber médico e à sua racionalidade.

A VIII Conferência Nacional de Saúde, realizada em 1986, representou o movimento de transformação do quadro da saúde no Brasil, pois possuiu caráter democrático e uma dinâmica processual. Esta conferência daria suporte para a elaboração da Constituição Federal de 1988, a qual incorporou a nova lógica referida pelos princípios da reforma sanitária e da saúde coletiva.

Para a Constituição, saúde é resultante das políticas sociais e econômicas, como direito de cidadania e dever do Estado e como parte da seguridade social. As ações e serviços de saúde devem ser providos por um Sistema Único de Saúde, mas, ao mesmo tempo, devem ser consagrados à liberdade de iniciativa privada. Com a Constituição Federal, se institucionaliza o Sistema único de Saúde SUS, que veio a ser regulamentado pelas leis orgânicas 8.080 e 8.142, de 1990, como provedor das ações e serviços que dizem respeito à saúde definidos na Carta Magna. O SUS delineia-se como alternativa ética e política ao modelo de assistência à saúde, na medida em que se configura como um modelo de atenção integral à saúde da população. Saúde passa a ser direito dos cidadãos e seus serviços e ações devem ser providos de forma descentralizada e submetidos ao controle social.

Os direitos da criança foram estabelecidos e reafirmados com a criação do Estatuto da Criança e do Adolescente - o ECA - em 1990, que representou um importante passo na construção de uma proposta de proteção integral à criança. O ECA considera criança a 
pessoa até os doze anos incompletos e atribui a ela todos os direitos fundamentais inerentes à pessoa humana,

a fim de Ihes facultar o desenvolvimento físico, mental, moral, espiritual e social, em condições de liberdade e de dignidade". A criança "têm direito à proteção à vida e à saúde, mediante a efetivação de políticas sociais públicas que permitam $o$ nascimento e o desenvolvimento sadio e harmonioso, em condições dignas de existência (BRASIL, 2001).

A saúde coletiva, como um campo de conhecimento e de práticas, contribui para recolocar a saúde como um problema a ser conhecido e que necessita de intervenções e políticas públicas de saúde que dêem conta da crítica ao modelo de saúde pública. Este conceito de saúde não considera apenas a dimensão biológica, mas inclui as dimensões simbólica, ética e política, privilegiando-se sua composição de forma transdisciplinar. A aproximação das ciências humanas, que vinha acontecendo desde 1920, ganha maior espaço, levando o SUS a voltar-se para os processos de produção de saúde, sejam eles formas de conhecimento ou tecnologias de cuidado, prevenção e manutenção da saúde. As práticas de atenção à saúde são orientadas pelo conceito de saúde, que entende como fatores determinantes à saúde as condições físicas, psicológicas e sociais, ou seja, os aspectos orgânicos, comportamentais e sociais constitutivos da forma de objetivar o ser humano em um ser biopsicossocial e que opera com um conceito de cidadania, dever e sujeito de direitos.

As crianças, a partir deste processo, possuem um campo específico de organização, formulação e execução de políticas no SUS. A saúde da criança está inserida como uma ação programática estratégica dentro da Atenção à Saúde. Para o Ministério da Saúde (BRASIL, 2008), atenção à saúde "é tudo que envolve o cuidado com a saúde do ser humano, incluindo as ações e serviços de promoção, prevenção, reabilitação e tratamento de doenças", e ações programáticas estratégicas são conteúdos programáticos, normas técnico-gerenciais, métodos e instrumentos que reorientem o modelo de atenção à saúde. O objetivo é promover o desenvolvimento de estratégias que permitam a organização da atenção à saúde, dando ênfase à atenção básica, visando fortalecer o acesso, a equidade e a integralidade das ações e serviços prestados etc (BRASIL, 2008).

A saúde da criança no Ministério da Saúde é operada pela Área técnica de Saúde da Criança e Aleitamento Materno e tem como objetivo elaborar, desenvolver e apoiar as diretrizes políticas e técnicas para atenção integral à saúde da criança de zero a 10 anos de idade, junto aos estados e municípios da União.

As políticas públicas de saúde direcionadas à população de zero a 10 anos de idade oferecem uma cobertura integral à saúde da criança. 
Para isso, criam uma série de intervenções de promoção, prevenção, terapêutica e recuperação de saúde. A principal preocupação do Ministério da Saúde com a saúde da criança é a diminuição dos índices de mortalidade que, em sua maioria, podem ser evitados se as crianças receberem atendimento resolutivo e qualificado.

O Ministério da Saúde, ao criar uma área técnica que trabalha especificamente com a atenção integral à saúde da criança, toma a infância como um momento de vida que deve ser investido de cuidados e atenção específica. Essa especificidade conferida à saúde da criança evidencia que o Ministério da Saúde considera a infância uma fase do desenvolvimento humano com características delimitadas e claras. A criança é investida pelo SUS como um momento específico de atenção à saúde, com vistas a dar um enfoque adequado às necessidades decorrentes das características relativas ao momento de vida em que as crianças se encontram. Neste contexto o Ministério da Saúde formulou a Caderneta de Saúde da Criança: passaporte da cidadania.

A Caderneta está disponível no portal do Ministério da Saúde como um documento inserido nas práticas de saúde direcionadas à criança, mais especificamente na Atenção à Saúde como uma ação programática estratégica - Saúde da Criança. Interessou-nos analisar a Caderneta não em tudo que ela contém, mas no que tange ao modo como se deu a articulação entre saúde e cidadania.

\section{Biopolítica e investimento na saúde da criança}

De acordo com Foucault (2006), a saúde é uma estratégia biopolítica. Assim sendo, a saúde da criança como um investimento político passa a garantir a produção do sujeito cidadão. A noção de biopolítica de Foucault, como estratégia do Estado, sobre a população e sobre os indivíduos, é importante para apontar como a vida, a saúde e os modos de viver foram colocados como uma preocupação e alvo de investimento das práticas do Estado. Portanto, a biopolítica torna visível os processos das políticas públicas, os quais vinculam as práticas dos governos às práticas de saúde, na produção dos sujeitos criança. Nesse sentido, tomamos as intervenções sobre a saúde das crianças como um conjunto de práticas, as quais instituem modos de ser sujeito, ou seja, os modos pelos quais os seres humanos tornamse sujeitos.

Durante a Idade Média, entre os séculos $\mathrm{V}$ e $\mathrm{XV}$, a infância não era considerada uma etapa do desenvolvimento como é atualmente. Com o início das estruturas de Estado moderno, isso se altera, pois o foco de interesse do Estado passa a ser o que está dentro do território e da sociedade, ou seja, o governo das pessoas e das coisas. A queda das estruturas feudais e, posteriormente, a Reforma e a Contra- 
Reforma, entre os séculos XVI a XVIII, possibilitaram que a infância fosse identificada como uma etapa da vida e, portanto, digna de cuidados específicos. Tal mudança se deveu em parte porque 0 Estado moderno integrou, numa forma política, uma tecnologia de poder originada no modelo de poder pastoral, exercido pelas pastorais católicas e protestantes de governo das pessoas. Essa integração do poder pastoral às estruturas do Estado moderno teria expandido o problema do governo das pessoas a toda a sociedade, criando novas tecnologias de governo. Já não se trata de dirigir as pessoas para a salvação após a morte, mas assegurá-la nesta vida, de forma a assumir a saúde, o bem-estar e a segurança como preocupações de governo (FOUCAULT, 2003). A ampliação das estruturas do poder pastoral representou um avanço do poder do Estado em direção a uma organização que individualiza e totaliza ao mesmo tempo os sujeitos. Nesse sentido, o Estado moderno ocidental construiu estratégias de poder muito fortes ao unir um poder político que é totalizador, preocupado com os interesses do conjunto das pessoas e, ao mesmo tempo, um poder individualizador. Essa preocupação com o como governar os indivíduos gerou uma multiplicação das formas de governo. A saber: o governo das crianças, dos pobres, das famílias, das casas, do exército, das cidades, dos Estados, do próprio corpo e do espírito (FOUCAULT, 2005).

Eram procedimentos de poder centrados "no seu adestramento, na ampliação de suas aptidões, na extorsão de suas forças, no crescimento paralelo de sua utilidade e docilidade, na sua integração em sistemas de controle eficazes econômicos," (FOUCAULT, 2003, p.151), caracterizando a anátomo-política do corpo humano. A anátomo-política consistia em procedimentos e técnicas de racionalização centradas no corpo individual que visavam distribuir racionalmente estes corpos no espaço, separando-os, alinhando-os, colocando-os em série e sob vigilância de forma a organizá-los em um campo de visibilidade. A anátomo-política, como tecnologia do poder disciplinar, age sobre os corpos e rege os indivíduos, vigiandoos, treinando-os, utilizando-os e punindo-os quando necessário. São técnicas de racionalização e de economia de um poder que deve agir de maneira menos onerosa possível através de um sistema de vigilância, de hierarquias, de inspeções, de escriturações e de relatórios, (FOUCAULT, 2003).

A partir da segunda metade do século XVIII, desenvolveu-se outra tecnologia de poder que não excluía a técnica disciplinar, mas que a integrava e a modificava. Não mais apenas o corpo individual atingiria esse poder, mas a vida dos homens, o homem enquanto ser vivo e espécie. Esse poder tomaria a população e não apenas o indivíduo como alvo de governo e como sujeito de necessidades. A racionalidade do governo passou a abarcar os processos disciplinares 
dos corpos e os processos regulamentares da vida e se colocou como regime de verdade que instituiu modos de ser e estar no mundo; uma biopolítica da população.

A biopolítica centrou-se no corpo-espécie como ser vivo e como suporte dos processos biológicos que se dirigiu ao conjunto das pessoas enquanto população. Foi, portanto, afetada por processos relativos à vida, como os nascimentos, a mortalidade, o nível da saúde, a duração da vida e a longevidade, submetendo tais processos a uma série de intervenções e controles reguladores. A vida passou a ser gerida em todos seus âmbitos, garantida, sustentada, reforçada e multiplicada ao longo de todo seu desenvolvimento. A morte, por ser o momento em que a vida escapa, tornou-se o limite de intervenção do poder. O governo teria como tarefa fazer as pessoas viverem e deixá-las morrer de acordo com padrões e regras específicas. (FOUCAULT, 2003)

A biopolítica como tecnologia de poder iria inaugurar um modo de governo baseado em mecanismos de regulamentação e não apenas de disciplina. Um poder sobre a "população enquanto tal, sobre o homem enquanto ser vivo, um poder contínuo, científico, que é o poder de fazer viver" (ALMA-ATA, 1978, s/p). A intervenção desse poder na população procuraria controlar as contingências dos fenômenos inerentes à vida de forma a controlar a probabilidade desses fenômenos para compensar seus efeitos. O poder exercido pela biopolítica seria cada vez menos o poder de fazer morrer e cada vez mais o poder para fazer viver no como da vida para otimizá-la ao máximo (ALMA-ATA, 1978).

A biopolítica criaria condições de agenciar o dispositivo do infantil, o infantil como uma qualidade, um estado, uma propriedade, como um modo de ser criança. O infantil passou a ser classificado, denominado, identificado, dito e medido pela razão, pelo discurso da verdade e pelas tecnologias do poder. A biopolítica, capaz de causar a vida, poderia investir na produção da infantilidade

por procedimentos de poder disciplinares; por fazer a anátomo-política do corpo infantil; e, através de intervenções e controles reguladores sobre a população, por realizar a biopolítica de uma população agora dividida em infantil e adulta. (CORAZZA, 2000, p. 21).

Assim sendo, a criança, a infância e o infantil seriam produzidos por esse dispositivo que os infantiliza. O poder estaria voltado para produzir a vida e ditar as características desses sujeitos que, se antes eram tratados sem distinção em relação aos adultos, agora passariam a ser uma etapa bastante distinta do desenvolvimento humano. Seria "o outro do adulto", como uma fase da vida que antecede o momento crucial: a fase adulta. O dispositivo do infantil produzirá a criança e o 
infantil envolta na dicotomização criança/adulto. A criança seria como a planta que precisa ser regada e adubada para que cresça e seja saudável e produtiva. A infância seria, ao mesmo tempo, uma fase que carece de investimentos, e também, e pelo mesmo motivo, uma fase de passagem, de incompletude que antecede o momento pleno de crescimento, raciocínio e desenvolvimento que será alcançado na fase adulta. A saúde da criança, nesse mesmo sentido, passou a ser merecedora de intervenções e de uma série de práticas específicas de saúde: cuidados com a gravidez, preocupações com o parto, com os primeiros dias de vida, com a alimentação diferenciada para cada etapa da infância, vacinação, etc. Investir na saúde da criança passou a significar investir no adulto que estaria por vir - uma série de leis, manifestos, estatutos, regras, instituições, profissões seriam criadas para dar conta dessa nova fase que se definia.

\section{Passaporte de Cidadania}

A problematização do documento deu-se a partir do título que possui - Caderneta de Saúde da Criança: Passaporte da Cidadania. Tal problematização poderia ter-se dado de diferentes maneiras. No entanto, essa foi escolhida, pois se compreendeu que o título poderia ser um importante disparador da discussão. Ao fragmentar-se o título em duas partes, tem-se Caderneta de Saúde da Criança e, após os dois pontos, passaporte da cidadania. O uso dos dois pontos remete à explicação, ao esclarecimento da idéia anunciada, ou seja, de que a Caderneta é um documento que leva as crianças a tornarem-se cidadãs. Passaporte é uma certidão de identidade internacional, válida em todo o mundo, que as pessoas usam para que possam circular por outros países que não os de sua nacionalidade. A Caderneta, concebida como passaporte, também pode ser entendida nesse sentido, pois, ao mesmo tempo em que confere às crianças uma identidade que lhes permite transitar pelo país, confere-lhes o título de cidadãs. É o que dá legitimidade para que as crianças possam sentir-se inseridas como habitantes da cidade e como indivíduos no gozo dos direitos do Estado, pelo menos no que diz respeito aos direitos concernentes à saúde, ao cidadão da saúde ou ao cidadão das políticas públicas de saúde. Isso pressupõe que os procedimentos e as prescrições de saúde, colocados ao longo da Caderneta, conduziriam a criança à posição de cidadã, podendo ser até mesmo compreendidos como uma garantia de cidadania.

Quando um documento de saúde direcionado às crianças propõe-se a ser passaporte de cidadania, oferecendo um modelo para o que seria a criança cidadã, tornam-se visíveis alguns efeitos de verdade na produção da infância pelas políticas de saúde do SUS. Um desses efeitos de verdade seria apontar que o status de cidadania é algo que 
se consegue mediante a filiação às práticas de saúde institucionalizadas nos serviços de saúde do SUS. Assim sendo, não se trata de um status natural, mas inscrito nas práticas de cuidado da saúde das crianças prescritas na Caderneta. A criança do SUS conforma-se, assim, como a criança cidadã, desde que sejam seguidas as orientações da Caderneta, do estatuto de saúde do Estado, e desde que se aceite esse modo de governo.

Para compreender os efeitos da afirmação de que a Caderneta produz cidadania, torna-se relevante problematizar como as políticas públicas de saúde constroem uma infância de direitos.

\section{Caderneta: a criança de direitos}

Desde o lançamento da noção de saúde, em 1947, pela Organização Mundial de Saúde (OMS), foram traçados os contornos que possibilitariam inscrever na Caderneta a realização do projeto de constituição da criança cidadã. A noção de saúde lançada nesse período definia saúde como estado de mais completo bem-estar físico, mental e social, e não apenas como a ausência de enfermidade, contrapondo-se à noção de saúde como ausência de doença vigente na saúde pública até então. Essa noção de saúde foi defendida na VIII Conferência Nacional de Saúde, em 1986. A conferência aportou importantes subsídios para o texto da Constituição Federal de 1988 no que se refere à saúde da população. De acordo com essa Constituição, a saúde passa a ser um direito do cidadão e um dever do Estado, que devem ser garantidos por políticas sociais e econômicas, visando um modo específico de saúde.

Art. 196. A saúde é direito de todos e dever do Estado, garantido mediante políticas sociais e econômicas que visem à redução do risco de doença e de outros agravos e ao acesso universal igualitário às ações e serviços para sua promoção, proteção e recuperação (BRASIL, 1988, s/p).

A lei orgânica do SUS, por sua vez, valeu-se dos mesmos direitos garantidos por essa Constituição para elaborar o conceito de saúde que orienta suas práticas atualmente. Entretanto, é a partir da repercussão que o alargamento dos direitos humanos passa a exercer na saúde que se possibilita ampliar esse conceito. Essa ampliação do conceito de saúde é parte de um processo mais amplo que redefiniu os modos de compreensão e investimento do Estado na vida da população.

Ocorre que, na primeira formulação da Declaração Universal dos Direitos Humanos, de 1789, se compreendiam direitos humanos como direitos civis e políticos como formas de promoção da 
cidadania. Esses direitos compreendiam a tolerância religiosa, o direito de viver sob o amparo da lei e a luta contra a tortura.

Naquele momento, esses direitos davam conta da necessidade de rompimento com o modo de governo absolutista, pois se vivia em um contexto de desenvolvimento dos Estados modernos e, por sua vez, do capitalismo. A Revolução Francesa seria um dos marcos de dissolução do modelo absolutista e, portanto, de invenção da burguesia. A Declaração dos Direitos do Homem e do Cidadão da Constituição Francesa de 24 de junho de 1793, diz:

O objetivo da sociedade é a felicidade comum. O governo é instituído para garantir ao homem o usufruto dos seus direitos naturais e imprescritíveis. Esses direitos são a igualdade, a liberdade, a segurança, a propriedade (GIACÓIA, 2008, p. 269).

Neste texto está implícito um dos preceitos do moderno estado democrático de direito: de que a justificação teórica não se encontra mais na vontade divina ou nos costumes herdados pela tradição, mas na natureza humana. A determinação colocada pelo estado democrático de direito e, em decorrência, pelos direitos humanos, enlaçaria homem e cidadão inaugurando um projeto de cidadania.

A construção do Estado moderno tornou a vida o foco dos investimentos do Estado, e não mais o território, como no absolutismo. A vida das pessoas deixou de ser um arbítrio do soberano para estar no centro das preocupações e investimentos. Nesse rumo, cria-se um campo vasto para dar conta do homem como sujeito de direitos: democracia representativa, cidadania e liberdade de expressão. Essa política da vida, como uma estratégia de biopolítica, tornou possível que se especifiquem, que se produzam conhecimentos, e que se criem instituições para potencializar a vida humana.

Isso gerou um movimento internacional que colocou as condições de vida da humanidade em evidência. $E$, nesse sentido, as discussões relativas aos direitos humanos opõem-se ao capitalismo e às más condições de vida, decorrentes das desigualdades provocadas por esse sistema. Depois da Declaração Universal dos Direitos Humanos, foram realizadas várias convenções pela ONU que colocaram em questão as minorias. Aqui começam a configurar-se ações e políticas que se voltam especificamente para a infância como um segmento diferenciado do restante da população e merecedor de atenção especial. Entre esses movimentos, é importante salientar a Conferência sobre os direitos da criança, de 1989, que apontou as crianças como grupo vulnerável e como alvo de preocupação internacional (VALADARES, 2008) - começa a constituir-se a ideia de 
uma criança cidadã ou, pelo menos, de uma criança portadora de direitos.

O bem-estar da população passou a relacionar-se a outros fatores como forma de evidenciar uma complexificação do humano. Estes estariam ligados ao trabalho, à moradia, à escola, ao lazer, à família, assim como à alimentação, à água, ao saneamento, à cultura, à diversão, ao transporte, entre outras formas de tornar-se humano. Cidadania, nesse contexto, é poder usufruir do arsenal de práticas que garantam boas condições de vida. No que concerne às crianças, o bem viver passou a abarcar práticas como: informar-se sobre a saúde da criança; observar o peso e altura ideais; fazer o teste do pezinho e do APGAR (avaliação da frequência cardíaca, respiração, musculatura, reflexos e cor da pele); vacinar; alimentar adequadamente; amamentar com leite materno; criar com afeto, oferecendo um ambiente saudável; garantir o acesso à escola, sem agressão para aprender; higienizar. Todas essas ações e práticas são descritas na Caderneta.

A Declaração dos Direitos Humanos, ao dissertar sobre os direitos da criança, afirmou a criança na perspectiva do humano. É na Declaração dos Direitos da Criança de 1959, porém, que a criança passa a ser considerada humana não apenas no âmbito geral dos direitos humanos, mas, também, na especificidade da infância. A Declaração dos Direitos da Criança teria sido um importante instrumento na produção da criança ao criar um âmbito específico onde a criança seria produzida. Os direitos da criança afirmariam que as crianças são sujeitos de características específicas - sujeitos que, em momento específico da vida, precisam ter respeitados e garantidos direitos que dêem conta de sua especificidade. Os direitos da criança funcionam, assim, como mecanismos subjetivadores que assujeitam as crianças e as produzem como sujeitos infantis.

Nas políticas públicas de saúde, a especificidade do infantil produz uma política específica para a saúde da criança e articula a saúde como um direito da criança que envolve os demais direitos relativos às condições de vida. Portanto, na Caderneta, a saúde é um direito que vincula direitos diversos: registro civil, alimentação, exames, acesso à saúde, acesso à escola, vacinação, ambiente, lazer e afeto. Isso produz uma ruptura com o modelo de saúde que considera que a saúde da criança envolve apenas os aspectos relacionados com 0 desenvolvimento e crescimento físico da criança. A ampliação dos direitos humanos e a especificidade conferida pela Declaração dos Direitos da Criança amarram a saúde a todos os fatores que dizem respeito à existência e ao momento de vida que estão passando essas crianças.

No entanto, de acordo com Deleuze (1992), a discussão de direitos humanos teria criado uma falsa ilusão de que todas as pessoas teriam condições de participação e de que o humanismo é uma 
realidade no mundo capitalista. De acordo com o autor, a única coisa de universal no capitalismo é o mercado, portanto, é uma fábrica incessante de riquezas e misérias. O Estado Democrático de Direito não considera as pessoas iguais perante a lei porque está comprometido com a fabricação da miséria humana para ser possível sustentar a produção de riquezas.

A vergonha é não termos nenhum meio seguro para preservar, e principalmente para alcançar devires, inclusive em nós mesmos. Como um grupo se transformará, como recairá na história, eis o que nos impõe um perpétuo cuidado. Já não dispomos da imagem de um proletário a quem bastaria tomar consciência (DELEUZE, 1992).

De acordo com Coimbra (2000), os direitos humanos teriam sido erguidos sobre uma noção de humano como sujeito universal ligado a uma essência e, portanto, como um objeto natural. Isso cria uma armadilha ao fundar uma noção universalizável de humano que vai considerar humanos apenas aqueles que estiverem de acordo com essas características:

(...) sempre estiveram fora desses direitos à vida e à dignidade os segmentos pauperizados e percebidos como "marginais": os "deficientes" de todos os tipos, os "desviantes", os miseráveis, dentre muitos outros. A estes, efetivamente, os direitos humanos sempre foram - e continuam sendo - negados, pois tais parcelas têm sido produzidas para serem vistas como "sub-humanas", como não pertencentes ao gênero humano (COIMBRA, 2000, p. 142).

Um caminho apontado por Coimbra é compreender direitos humanos não a partir de uma essência humana imutável e universal, mas a partir de outras construções que afirmem as diferentes formas de manifestação do humano. Uma forma de afirmar "direitos locais, descontínuos, fragmentários, processuais, em constante movimento e devir, provisórios e múltiplos como as forças que se encontram no mundo" (COIMBRA, 2000, p. 142).

Essa crítica em relação aos direitos humanos universais pode ser tomada como referência para a problematização das políticas de atenção à saúde da criança, ao nos questionarmos em que medida a "Caderneta de Saúde da Criança: passaporte de cidadania" permite que se articule diferentes modos de ser criança nas práticas de saúde do SUS. Em análise realizada na Caderneta vemos coexistir no documento tanto a perspectiva da Saúde Pública quanto da Saúde Coletiva.

As ações de saúde pública, por se fundarem em ciências positivas e por se pautarem em noções onde a biologia é utilizada como modelo central para explicar e intervir na relação entre saúde e doença, filiam-se ao modo como os sujeitos são explicados como espécie 
biológica. Divide, portanto, o humano em corpo e mente. E, neste sentido, fixam os sujeitos em um modo rígido de ser sujeito. Essas técnicas de fixação estão presentes na organização e na lógica das práticas de saúde da Caderneta de Saúde da Criança. Essa lógica atravessa a construção da Caderneta a partir de uma lógica linear e gradativa de cuidados e ações de saúde que vão investindo na criança ao longo de seu crescimento e desenvolvimento.

A saúde da criança, por meio das práticas da Caderneta, recebe o recém-nascido numa rede de cuidados e de atenção à saúde que vai aos poucos o inserindo nos padrões e regulamentos da sociedade. Dessa forma, as práticas de atenção e cuidado da saúde constroem e modificam a experiência que os indivíduos têm de si, através de mecanismos que colocam em funcionamento um tipo de relação do sujeito consigo mesmo que produzem e transformam a experiência de si. O resultado do processo de fabricação em que se cruzam os discursos que definem a verdade do sujeito, as práticas que regulam seu comportamento e as formas de subjetividade constituem uma interioridade (LARROSA, 1994). São elementos que vão atribuindo características a essas crianças recém chegadas, tanto em relação ao que seus corpos evidenciam quanto à inscrição desta em determinada família, país, cidade e meio social. A infância, por ser considerada pela política pública de saúde a primeira etapa do desenvolvimento da vida, é o momento em que a pessoa recebe suas primeiras atribuições e, neste sentido, constitui os modos de ser e viver a infância.

Essa compreensão desenvolvimentista pauta, inicialmente, a classificação das práticas de atenção integral à saúde da criança desde o nascimento até a idade de 10 anos. Logo em seguida, define, a partir dos padrões existentes em cada idade, que práticas são mais apropriadas e adequadas a um desenvolvimento saudável do infante. Esse entendimento se conecta às classificações e divisões que a modernidade desenvolveu para explicar como os seres humanos se desenvolvem de acordo com a idade cronológica - infância, adolescência, idade adulta e velhice. A partir da predominância de padrões de desempenho que se dá em cada fase, um padrão é alçado à condição de normalidade e, baseando-se nele, constroem-se as intervenções na saúde da criança. É assim que a Caderneta organiza as ações, ou seja, em acordo com as necessidades consideradas predominantes em cada momento do desenvolvimento da criança.

Portanto, os saberes que estão presentes na Caderneta conformam e produzem os modos como a criança, ao ser investida por práticas de saúde, acabam por se relacionar consigo e com o mundo de acordo com as prescrições de saúde. Isso direcionará a criança a se perceber pelas características de cada idade, por possuir ou não uma patologia, por organizar suas tarefas diárias a partir de algumas práticas de higiene e alimentação, como ter horários para o banho, 
para a higiene bucal, para as refeições. Irá definir, a partir dos conhecimentos cognitivos, o momento adequado para aprender a ler, a escrever, etc. As práticas de saúde ao definirem os parâmetros de normalidade e prescreverem as rotinas às crianças, criam disfunções e anormalidades no comportamento infantil. A criança que não estiver dentro desses parâmetros e regulamentações precisará maiores investimentos para aproximá-la ao máximo da "normal".

Esse modo de organização é herança das práticas de saúde anteriores à construção do SUS. Isso denota que essas práticas não se extinguiram, mas continuam coexistindo na concepção que orienta as práticas contidas na Caderneta. O perigo é tomar tais orientações como parâmetros absolutos para todas as intervenções em saúde, pois essas generalizações sobre a vida das pessoas não consideram os fatores contingenciais relativos à vida em movimento.

A saúde coletiva, por outro lado, como forte influência nas práticas de saúde do SUS, é uma possibilidade para a não absolutização das práticas em saúde. A saúde coletiva, por procurar dar conta dessa multiplicidade e provisoriedade, traz para a saúde da criança condições de outros modos de produção de viver e de se relacionar consigo e com os outros. A saúde coletiva é fruto das reivindicações de mudança do movimento sanitário e, por isso, pode ser uma possibilidade de considerar que diferentes formas de ser criança podem ser contempladas nas práticas de saúde. Ela propõe uma crítica ao projeto médico-naturalista e nega que os discursos biológicos detenham o monopólio do campo da saúde. A problemática da saúde deve incluir as dimensões simbólica, ética e política, privilegiando-se diferentes modos de produção de sujeitos (BIRMAN, 1991). As práticas de atenção à saúde são orientadas pelo conceito de saúde, que entende como fatores determinantes à saúde as condições físicas, psicológicas e sociais, ou seja, os aspectos orgânicos, comportamentais e sociais constitutivos da forma de objetivar o ser humano em um ser biopsicossocial.

Este entendimento amplia as intervenções da atenção à saúde das crianças e criam uma série de intervenções sobre elas, como cuidados relativos ao ambiente em que vivem, à alimentação, ao afeto e à segurança. Na Caderneta, a diversidade de cuidados de que fala o conceito de saúde aparece na amplitude das intervenções que indica aos pais e profissionais de saúde as práticas de atenção à saúde da criança, tais como: o ambiente saudável, a alimentação/amamentação saudável, a saúde bucal, observe o que o seu filho ou filha já consegue fazer, desenvolva-o com afeto e segurança de acordo com as exigências da idade, saúde ocular, saúde auditiva, perímetro encefálico, vacinação (BRASI L, 2007).

Ao longo do desenvolvimento, a Caderneta estimula que os pais e as crianças se entendam e isso faça com que eles reconheçam as necessidades e jeitos de ser da criança. A infância é compreendida 
como uma importante etapa do desenvolvimento e que possui peculiaridades de acordo com a idade e o contexto em que vivem. Elas são identificadas como sujeitos que possuem sentimentos e que precisam se desenvolver com afeto. "As crianças são sensíveis e, desde, o nascimento, são capazes de diferenciar um tom de voz carinhoso de um tom agressivo" (BRASIL, 2007, p. 36).

No entanto, para que não seja realizada uma discussão estanque dos efeitos da Caderneta na produção da saúde da criança é preciso levar em conta que não se trata de um juízo de valor ou de uma divisão entre as práticas que pertencem à saúde coletiva e as que pertencem à saúde pública. Não se procura afirmar que as práticas de saúde pública sejam ruins e que as de saúde coletiva sejam boas. Mas que ambas tratam de modos de governo da população como estratégias biopolíticas que, ao investirem na vida, regulamentam e normatizam a vida dos sujeitos. Portanto, a saúde coletiva não é aqui analisada como um campo capaz de "salvar" a infância das práticas de governo, mas procurar apontar que condições a saúde coletiva pode oferecer para que diferentes governos do infantil possam ser engendrados. Modos de governos mais plurais que sejam menos prescritivos e possibilitem potencializar diferentes formas de as crianças e os cuidadores se relacionarem com sua saúde. Dessa maneira, a diversidade de práticas de saúde que a noção de integralidade traz, a partir da saúde coletiva, pode ser compreendida também como uma ampliação do controle exercido pelo governo biopolítico através da sofisticação das práticas de saúde mesmo sendo considerada como uma crítica à saúde pública.

Essa gama diversificada de práticas que se preocupam com a integralidade das ações pode ser identificada como um manual de como ser pai e de como ser filho e estar ditando as formas mais adequadas de cuidar da saúde da criança. A Caderneta estaria seguindo a tendência de criar manuais de como ser pai, mãe, filho, empreendedor, ser professor ou ser qualquer coisa na sociedade atual. A Caderneta quando tomada como um discurso de verdade produz discursos especializados sobre a criança e se coloca acima dos demais saberes que estão presentes na sociedade sobre a saúde da criança. Esses manuais, e, em especial a Caderneta, pode ser de grande ajuda para orientar os pais ou cuidadores sobre como cuidar da saúde da criança, mas pode desqualificar o cuidador ao desconsiderar os conhecimentos e intuições que eles trazem. Isso estaria baseado em um a priori de que os pais não têm condições de cuidar dos seus filhos.

Essa amplitude de práticas que a saúde coletiva possibilita na construção da Caderneta não desconsidera que as práticas de saúde da criança sejam uma estratégia de governo que produz os indivíduos nas relações de poder. O SUS é uma política que investe na vida e produz o modo como as pessoas cuidam de si e lidam com sua saúde, 
como política que se tornou central na vida das pessoas. Mas considera que essas estratégias ocorrem em um campo múltiplo que irá articular o saudável a fatores que antes não eram considerados como existenciais, psicológicos e ou sociais. Isso possibilita uma diversificação nos modos como o poder irá produzir os sujeitos. Podese dizer então que a Caderneta, ao possuir um conceito de saúde ampliado, possibilita que a complexidade, diversidade e amplitude da produção de vida possam ter maiores condições de pautar os efeitos das intervenções de saúde de forma a não, necessariamente, privilegiar um modo de se produzir a infância, mas uma multiplicidade de modos. Nesse sentido, a construção do SUS pode ser uma condição de abertura à multiplicidade de produção de sujeitos e de saúde, embora não se veja livre de algumas contradições.

A saúde coletiva é um movimento que dita modos de existência e que elenca verdades científicas sobre a vida da população, mas representa também uma possibilidade de escolha sobre os modos como esperamos que sejam essas verdades. $E$, portanto, pode ser um lugar interessante para estarmos a todo o momento nos indagando sobre o modo como queremos ser governados. Com isso, não estamos querendo dizer que possamos atingir um momento que nos colocaremos fora de estratégias de governo, mas que podemos nos colocar em uma posição onde é possível saber como somos governados e, assim escolhermos outros modos, que não os colocados, de sermos governados.

A saúde coletiva ao trazer para o SUS uma nova proposta de sistema de saúde e, principalmente, de conceito de saúde e da política de atenção de modo geral consegue fazer algumas resistências às práticas universalizantes que acabam por fixar os indivíduos em determinados modos de ser e estar no mundo. O que não exclui, como descrito acima, que a saúde pública não esteja imersa nas práticas oficiais do SUS. A nova proposta de saúde do SUS, ao trazer para o campo da saúde diferentes aspectos que não apenas os fatores relacionados ao adoecimento, está ligada a modos de percepção de identidades cambiantes e abertas aos diferentes movimentos que o viver coloca às pessoas. Assim como está vinculada, ao mesmo tempo, à identidade sociológica que acaba conferindo às práticas de saúde um terreno que fixa os sujeitos em um modo de ser de acordo com verdades estabelecidas. Portanto, a Caderneta de Saúde da Criança: passaporte de cidadania fixa e faz a infância circular por diferentes modos de compreensão de sujeitos, ao mesmo tempo. 


\section{Saúde e Cidadania}

A discussão sobre a Caderneta de saúde da criança: passaporte da cidadania evidencia como a Caderneta articula saúde, criança e cidadania. Diante disso, a questão inicial deste artigo problematização das práticas de saúde da criança - vai ao encontro da produção da criança cidadã. O SUS, como resultado do atravessamento de diferentes práticas de saúde, produz os cuidados à saúde da criança a partir de um conceito de saúde que compreende a infância como uma fase da vida que carece de investimentos que produzam a criança como cidadã. A infância da saúde coletiva é uma infância de direitos. Ela decorre de todo um processo histórico que tornou a infância uma fase da vida que necessita de cuidados de saúde. Mais tarde, esses cuidados de saúde se complexificaram, e ampliaram os fatores envolvidos na produção da infância cidadã.

Portanto, o SUS, ao atrelar a saúde à cidadania, traz a preocupação do Estado moderno de garantir que os sujeitos atinjam o status de cidadania. Esse status, a partir dos movimentos dos Direitos Humanos, carrega direitos civis e políticos, mas inclui direitos econômicos, sociais, culturais e ambientais, decorrentes do processo de ampliação dos fatores que compõem o bem-estar do humano. $O$ SUS, através da Caderneta, procura articular suas práticas ao exercício dos direitos políticos, civis, econômicos, sociais, culturais e ambientais do infante. No entanto, é preciso não perder de vista que a Caderneta, inscrita nas estratégias de governo da biopolítica, nos coloca em constante vigília dos processos de regulamentação da existência a que estamos sujeitados.

Não podemos naturalizar os cuidados que direcionamos a nós mesmos; devemos entendê-los como parte de um poder que quantifica, mede, avalia, hierarquiza e distribui os indivíduos em torno da normalização da vida. Em suma, qualifica e amplia os fatores envolvidos na produção de sujeitos. A saúde cria um campo de verdade em torno da criança e de técnicas para produzi-la que acaba por instituir práticas que constitui e transforma a experiência de si. Ao se conhecerem essas diferentes maneiras, pode-se não aceitar esse conhecimento ingenuamente, mas como jogos de verdade específicos relacionados a técnicas que as pessoas utilizam para entender a si mesmas.

Assim, os cuidados à saúde da criança produzem saberes e práticas que não necessariamente abarcam as diferentes formas possíveis de as crianças construírem-se como sujeitos, mas podem privilegiar apenas um modelo de infância. Trata-se de estarmos atentos aos perigos de colocarmos os cuidados de saúde direcionados às crianças como verdades que sustentam práticas com padrões imutáveis e rígidos - os cuidados precisam ser entendidos numa dinâmica flexível que precisa estar em constante modificação. Isso não 
necessariamente implica considerarmos como possível uma verdade sobre as práticas de cuidado à saúde da criança; não há um modelo certo e outro errado. A saúde coletiva não é a resposta e ela está imersa em diferentes jogos que produzem os modos de ser no contemporâneo.

As práticas de cuidado com a saúde da criança são partes de um terreno movediço e instável, característico da coexistência de várias lógicas. Na medida em que permitem práticas de cuidado vinculadas às problematizações e ampliações propostas pela saúde coletiva, possibilitam abarcar e produzir diferentes modos de produção de sujeitos; são construídas por práticas de saúde previamente estabelecidas por um parâmetro de sujeito normal.

A construção do SUS pode ser uma condição de abertura à multiplicidade de produção de sujeitos com base em práticas de governo mais plurais, o que pode configurar uma crítica ao governo operado pelas políticas de saúde direcionadas às crianças. É preciso que estejamos sempre atentos às práticas que congelam a existência em noções rígidas de como lidar com nós mesmos.

\section{Referências}

ALMA ATA. Declaração de Alma-Ata. Conferência Internacional sobre cuidados primários de saúde. Organização Pan-Americana da Saúde. Brasília, $1978 . \quad$ Disponível em: <http://www.opas. org.br/coletiva/uploadArq/Alma-Ata. pdf>. Acesso em: 29 jan. 2009.

BIRMAN, J. A Physis da Saúde Coletiva. Physis - Revista de Saúde Coletiva, v. 1, n. 1, p. 7-12, 1991.

BRASIL. Constituição da República Federativa do Brasil de 1988. Presidência da República Federativa do Brasl. 1988. Disponível em:

<http://www. planalto.gov.br/ccivil_03/constituicao/constitui\% C3\% A7 ao.htm>. Acesso em: 29 jan. 2009.

BRASIL. Estatuto da Criança e do adolescente: Lei n.8.069, de 13 de julho de 1990. 3. ed. Brasília: Câmara dos deputados, Coordenação de Publicações, 2001.

BRASIL. Ministério da Saúde. Caderneta da Saúde da Criança. 2a Tiragem. Secretaria de Saúde do Estado de Minas Gerais. Belo Horizonte, 2007.2 Disponível em: <http://www.saude.mg.gov.br/publicacoes/linha-guia/linhasguia/Atencao\% 20a\% 20Saude\% 20da\% 20Crianca.pdf>. Acesso em: 1 jul. 2008.

BRASIL. Portal do Ministério da Saúde. Ministério da Saúde. Brasília, 2008. Disponível em: 
<http://portal.saude.gov.br/portal/saude/default.cfm>. Acesso em: 1 jul. 2008.

COIMBRA, C. M. B. Psicologia, Direitos Humanos e Neoliberalismo. Revista Psicologia Política, Belo Horizonte, v. 1, n. 1, p. 139-148, jan./jun. 2000.

CORAZZA, S. M. História da infância sem fim. Ijuí: UNIJ UÍ, 2000.

DELEUZE, G. Conversações. Rio de Janeiro: Editora 34, 1992.

FOUCAULT, M. História da sexualidade I: a vontade de saber. 15a ed. São Paulo: Edições Graal, 2003.

FOUCAULT, M. Em defesa da sociedade: curso no Collège de France (1975-1976). São Paulo: Martins Fontes, 2005.

FOUCAULT, M. A governamentalidade. In:

1926-1984. Estratégia, poder-saber. 2a ed. Rio de Janeiro: Forense Universitária, 2006, p. 282-305.

GIACÓIA, J. O. Sobre direitos humanos na era da bio-política. Revista Kriterion 2008, Belo Horizonte, v. 49, n. 118, p. 267-308, Dez. 2008.

LARROSA, J. Tecnologias do Eu e Educação. In: SILVA, T. T. (Org.). O Sujeito da Educação: Estudos Foucaultianos (35-86). Petrópolis: Vozes, 1994.

MACHADO, R. Por uma genealogia do poder. In: FOUCAULT, M. Microfísica do Poder. 19a ed. Rio de Janeiro: Edições Graal, 2004, p. VII-XXIII.

MATTOS, R. A. Os sentidos da integralidade: a algumas reflexões acerca de valores que merecem ser defendidos. In: PINHEIRO, R.; MATTOS, R. A. (Org.). Os sentidos da integralidade na atenção e no cuidado à saúde. $3^{a}$ ed. Rio de Janeiro: UERJ; IMS: ABRASCO, 2001, p. 39-64.

VALADARES, T. Conferência conjuntura nacional: desafios aos direitos humanos. In: CFP (Conselho Federal de Psicologia). Psicologia e direitos humanos: desafios contemporâneos. São Paulo: Casa do Psicólogo, 2008, p. 21-38.

\section{Endereço para correspondência}

Lutiane de Lara

Rua Riachuelo, 359, apto 704 - Porto Alegre/ RS-90010-273

Endereço eletrônico: lutianelara@yahoo.com.br

Neuza Maria de Fátima Guareschi

Rua General Souza Doca, 270 - Porto Alegre/ RS-90630-050

Endereço eletrônico: nmguares@gmail.com

Simone Maria Hüning

Av. Lourival Melo Mota, s/n, Tabuleiro do Martins - Maceió- AL, CEP: 57072-970

Endereço eletrônico: simonehuning@yahoo.com.br 
Recebido em: 26/08/2010

Reformulado em: 08/10/2010

Aceito para publicação em: 15/02/2011

Acompanhamento do processo editorial: Deise Mancebo

\section{Notas}

* Mestre em Psicologia pelo PPGP/ PUC-RS (Pontifícia Universidade Católica do Rio Grande do Sul). Doutoranda PPGPSI/UFRGS (Universidade Federal do Rio Grande do Sul) - Bolsista Capes.

** Pesquisadora do PPGSI/UFRGS (Universidade Federal do Rio Grande do Sul). Coordenadora do Grupo de Pesquisa Estudos Culturais e Modos de Subjetivação. *** Doutora em Psicologia pelo PPGP PUCRS. Professora da UFAL/Universidade Federal de Alagoas - ICHCA- Curso de Psicologia. 